\section{Botulinum toxin to improve lower facial symmetry in facial nerve palsy}

SA Sadiq ${ }^{1,2}$, S Khwaja ${ }^{3}$ and SR Saeed ${ }^{4}$

\begin{abstract}
Introduction In long-standing facial palsy, muscles on the normal side overcontract causing difficulty in articulation, eating, drinking, cosmetic embarrassment, and psychological effects as patients lack confidence in public.

Methods We injected botulinum toxin A (BTXA) into the normal contralateral smile muscles to weaken them and restore symmetry to both active and passive movements by neutralising these overacting muscles.

Results A total of 14 patients received BTXA (79\% women, median age 47 years, average length of palsy 8 years). They were all difficult cases graded between 2 and 6 (average grade 3 House-Brackmann). All 14 patients reported improved facial symmetry with BTXA (dose altered in some to achieve maximum benefit). Average dose was 30 units, but varied from 10 to 80 units. Average time to peak effect was 6 days; average duration of effect was 11 weeks. Three patients had increased drooling (resolved within a few days).

Conclusion The improvement in symmetry was observed by both patient and examining doctor. Patients commented on increased confidence, being more likely to allow photographs taken of themselves, and families reported improved legibility of speech. Younger patients have more muscle tone than older patients; the effect is more noticeable and the benefit greater for them. BTXA improves symmetry in patients with facial palsy, is simple and acceptable, and provides approximately 4 months of benefit. The site of injection depends on the dynamics of the muscles in each individual patient. Eye (2012) 26, 1431-1436; doi:10.1038/eye.2012.189; published online 14 September 2012
\end{abstract}

Keywords: facial palsy; botulinum toxin; symmetry

\section{Introduction}

In facial palsy, paralysis of muscles on the affected side of the face results in loss of forehead creases, loss of the nasolabial fold, lagophthalmos, brow droop, and drooping of the corner of the mouth. In contrast, muscles on the unaffected side of the face no longer have opposing forces. ${ }^{1}$ This may cause difficulty in articulation, eating, drinking, and is often cosmetically unacceptable to patients because of asymmetry, especially when speaking, smiling, and laughing. There are significant

psychological effects as patients lack the confidence to carry out many daily activities in public, such as appearing in photographs.

Although management is difficult, there are a range of reanimation options available. These include nerve grafts, muscle transfers, myofunctional approaches, and microsurgical patches usually for the more severe facial palsies (House-Brackmann grades 4 to 6$)^{1}$ However, despite these procedures, facial symmetry may not improve.

Botulinum toxin A (BTXA) has been used since the 1970s to treat a variety of conditions resulting in abnormal muscle contraction or spasm. It works by preventing the release of acetylcholine into the neuromuscular junction thereby inhibiting muscle contraction. ${ }^{2}$ Its benefits in synkinesis in facial palsy (aberrant neural regeneration of the paralysed muscles) are well recognised. ${ }^{1,3}$

Our aim was to document the use of BTXA injections to the unaffected side to improve symmetry in patients with facial nerve palsy. BTXA was administered to the normal lower side, which exaggerates the asymmetry (especially on movement such as smiling) in order to reduce this asymmetry.

BTXA was injected into the contralateral lower facial muscles complex to weaken the unopposed normal muscles to improve
${ }^{1}$ Manchester Royal Eye Hospital, Manchester, UK

${ }^{2}$ The University of Manchester, Manchester Academic Health Science Centre, Central Manchester Foundation Trust,

Manchester, UK

${ }^{3}$ Department of Otolayngology, Manchester Royal Infirmary, Manchester UK

${ }^{4}$ National Ear, Nose and Throat Hospital, London, UK

Correspondence:

SA Sadiq, Manchester Royal Eye Hospital, Oxford Road, Manchester M13 WH, UK Tel: +44 (0)161 276 8957; Fax: +44 (0)1616602310.

E-mail: a.sadiq@

manchester.ac.uk

Received: 23 April 2012 Accepted in revised form: 25 June 2012

Published online:

14 September 2012

Presented as an oral communication at the: XIth International Facial Nerve Symposium in Rome, 2009 and British Oculoplastic Surgery Society Annual Meeting 2010. 
symmetry, both active and passive. This is similar to the way that BTXA is injected into the medial rectus muscle in abducens palsy to prevent contracture and reduce ocular convergence, ${ }^{3}$ thus neutralising the opposing forces. ${ }^{4}$

Mime therapy consisting of massage, relaxation, inhibition of synkinesis, and co-ordination and emotional expression exercises can improve facial symmetry, but unfortunately this treatment is not easily accessible to patients. $^{5}$

\section{Materials and methods}

A retrospective case note review of consecutive patients with facial nerve palsy receiving BTXA therapy to the contralateral lower facial muscle complex at the Manchester Royal Eye Hospital, UK was undertaken.

Data collected included age, gender, diagnosis, severity of palsy (House-Brackmann grading scale for facial palsy), dose of BTXA (Dysport), number of treatment sessions, length of time taken for peak effect to occur, how long the effect lasted, and any side effects experienced. All injections were given by the senior consultants (SAS and SRS).

\section{Surgical steps}

1. Patients are seated in upright position with the head supported.

2. Mark out points of maximum unopposed muscle pull on unaffected side. The sites of injection were determined by clinical assessment, that is, in the area exhibiting the greatest pull on movement of the lower face (usually the patient was asked to smile widely). See Figure 2.

3. In all, 500 units of Dysport made up with $5 \mathrm{ml}$ of saline, that is, 10 units per $0.1 \mathrm{ml}$.

4. Dysport was injected at an angle of $45^{\circ}$ intramuscularly to each site using an insulin syringe.

5. Needle EMG was not used to guide injection of BTXA. Specific muscles co-ordinating the smile were not targeted, but rather an area of activity that was contributing most to the movement of the lower face on the normal side during smiling. Although it is not possible to be accurate as to the specific smile muscles injected (see Figure 1), from the patients' injection site diagrams, it is likely that the sites of BTXA injection corresponded to the depressor anguli oris (DAO) in eight cases, levator labii superioris (LLS) in one patient, both DAO and LLS in four patients, and DAO with nasojugal fold in one patient. It is very likely that the zygomaticus and risorius muscle were also treated as part of the active muscle area.

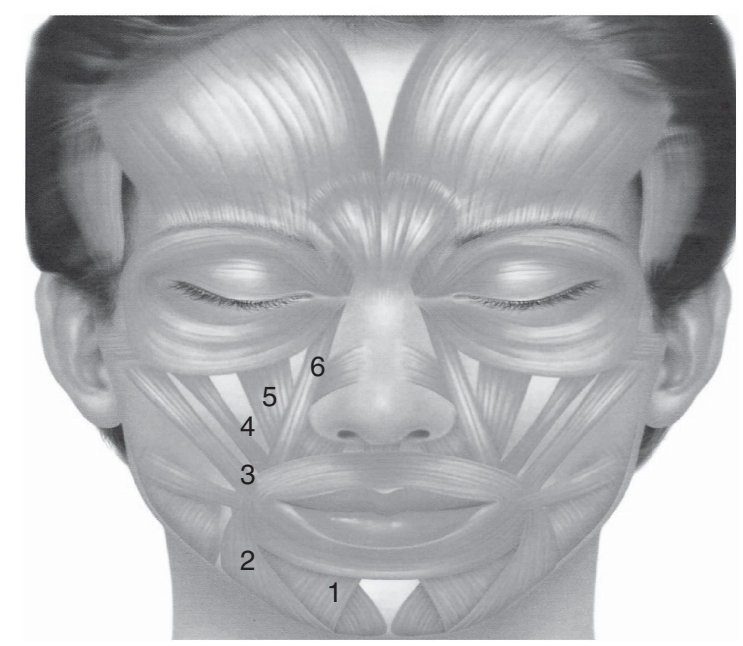

Figure 1 The smile muscles: 1, depressor labii inferioris; 2, depressor anguli oris; 3 , zygomatic major; 4, zygomatic minor; 5 , levator labii superioris; 6 , levator labii superioris alaeque nasi.

\section{Results}

A total of 14 patients underwent BTXA injection to the contralateral lower facial muscle complex, (Table 1). In all, 11/14 (79\%) were women. The median age was 47 years (range $12-68$ years).

In total, 6/14 (42.9\%) of the facial palsies were caused following or before surgery for a vestibular schwannoma. The ratio of left to right side facial palsy was $1: 1$. The average duration of the facial palsy was 8 years (range 1-34 years). All patients were between HouseBrackmann grades 2 and 6 , with the average grade being 3 .

All reported a subject improvement in facial symmetry following injections, although the dose did have to be altered in some patients to achieve the maximum benefit. The mean injection dose of BTXA was 30 units (range 10-80 units, see Table 2). Most patients were started on between 15 and 25 units, which was then titrated depending on the outcome. The average time to peak effect was 6 days (range 1-21 days). The average duration of effect was 13 weeks (range 7-24 weeks). The average number of sessions was 5 (range 1-15).

Surface electromyography studies (Figures 2a and b) show a reduction in muscle activity at the corner of the mouth on smiling on the unaffected (ie, non-palsy) side post-BTXA injections. The ratio of mean muscle activity on each side is used as a measure of symmetry. Pre-BTXA the ratio of affected: unaffected side is $1: 9$. Post-BTXA this reduces to $1: 1$, which we believe accounts for the improved symmetry.

Only four patients experienced side effects: drooling lasting 3-7 days (three patients) or difficulty in producing the sound ' $\mathrm{f}$ ' (one patient), but this did not deter them from further treatments with BTXA. 
Table 1 Demographics and aetiology

\begin{tabular}{lclcc}
\hline Patient & Age (years) & Aetiology & Duration of palsy (years) & House-Brackmann grade \\
\hline 1 & 64 & Vestibular schwannoma & 5 & 6 \\
2 & 12 & Congenital facial weakness & 12 & 2 \\
3 & 51 & Vestibular schwannoma & 7 & 3 \\
4 & 68 & Vestibular schwannoma & 1 & 3 \\
5 & 50 & Poliomyelitis & 34 & 2 \\
6 & 52 & Vestibular schwannoma & 5 & 4 \\
7 & 44 & Facial schwannoma & 5 & 2 \\
8 & 46 & Bell's palsy & 2 & 3 \\
9 & 43 & Parotid carcinoma (muco-epidermoid) & 3 & 3 \\
10 & 16 & Skull base fracture & 5 & 3 \\
11 & 42 & Vestibular schwannoma & 12 & 3 \\
12 & 62 & Vestibular schwannoma & 4 & 3 \\
13 & 67 & Vestibular schwannoma & 3 & 6 \\
14 & 47 & Cholesteatoma & 2 & \\
\hline
\end{tabular}

Table 2 Site, Dosage, and effect of BTXA

\begin{tabular}{|c|c|c|c|c|c|c|c|}
\hline Patient & Grade & $\begin{array}{l}\text { Number } \\
\text { of sessions }\end{array}$ & $\begin{array}{l}\text { Main muscle } \\
\text { injection site }\end{array}$ & Dose & Side effects & $\begin{array}{c}\text { Time taken } \\
\text { for effect } \\
\text { (days) }\end{array}$ & $\begin{array}{c}\text { Period } \\
\text { of action } \\
\text { (months) }\end{array}$ \\
\hline 1 & 6 & 5 & Depressor angularis oris & $\begin{array}{l}20 \text { Units, increased to } 30 \text { units on } \\
\text { fourth session }\end{array}$ & $\begin{array}{l}\text { Drooling } \\
\text { for } 3 \text { days }\end{array}$ & & \\
\hline 2 & 2 & 4 & Elevator angularis oris & 10 Units no effect, then 20 units effective & - & 3 & 3 \\
\hline 3 & 3 & 6 & $\begin{array}{l}\text { Elevator and depressor } \\
\text { angularis oris }\end{array}$ & 20 Units, 10 each to depressor and elevator & - & 4 & 5 \\
\hline 4 & 3 & 6 & Depressor angularis oris & 40 Units & - & 3 & 2 \\
\hline 5 & 2 & 15 & Depressor angularis oris & 15 Units then 20 units from fifth session & $\begin{array}{l}\text { Drooling } \\
1 \text { week }\end{array}$ & 4 & 3 \\
\hline 6 & 4 & 5 & $\begin{array}{l}\text { Elevator and depressor } \\
\text { angularis oris }\end{array}$ & $\begin{array}{l}25 \text { Units reduced to } 20 \text { units after } \\
\text { fourth session }\end{array}$ & - & 4 & 2 \\
\hline 7 & 2 & 11 & $\begin{array}{l}\text { Two areas of depressor } \\
\text { angularis oris }\end{array}$ & $\begin{array}{l}\text { Started at } 15 \text { units and titrated up. } \\
\text { No effect until } 80 \text { units }\end{array}$ & - & 7 & 2 \\
\hline 8 & 2 & 2 & Depressor angularis oris & 20 Units & - & 1 & 6 \\
\hline 9 & 3 & 4 & Depressor angularis oris & 20 Units increased to 30 units at third session & - & 10 & 2 \\
\hline 10 & 3 & 3 & $\begin{array}{l}\text { Elevator and depressor } \\
\text { angularis oris }\end{array}$ & 20 Units increased to 30 as no effect & - & 21 & 3 \\
\hline 11 & 3 & 4 & Depressor angularis oris & 20 Units, increased to 30 as no effect & - & & \\
\hline 12 & 4 & 1 & Depressor angularis oris & 25 Units & - & 4 & 4 \\
\hline 13 & 3 & 7 & $\begin{array}{l}\text { Elevator and depressor } \\
\text { angularis oris }\end{array}$ & 20 Units & Drooling & 4 & 4 \\
\hline 14 & 6 & 1 & $\begin{array}{l}\text { Depressor angularis oris } \\
\text { and nasolabial fold }\end{array}$ & 25 Units and 10 units & $\begin{array}{l}\text { Loss of } \\
\text { 'f } \mathrm{f} \text { ' }\end{array}$ & 3 & 4 \\
\hline
\end{tabular}

Figure 2 shows a patient before and 10 days post-BTXA injection. Figure 3 shows a patient before and 1 month post-BTXA injection.

\section{Discussion}

No face has true facial symmetry at rest or on active movement. ${ }^{6}$ When a unilateral facial palsy affects this balance between the left and right sides of the face, the degree of asymmetry affects quality of life and daily function. Restoring symmetry is important to allow normal functioning of the mouth and to improve psychological wellbeing.

BTXA has been described for facial hyperkinesis on the non-affected side ${ }^{1}$ but used a higher total dose with a similar effective duration of action. ${ }^{1}$ With the average dose required being 30 units, we feel it is reasonable to start the first session with 20 units, and titrate as necessary. There were sometimes difficulties in finding the appropriate dosage, for example, in one lady, there was no effect until 80 units were injected. However, once an effective dose was reached, the improvement in symmetry was observed by both the patient and the 
a

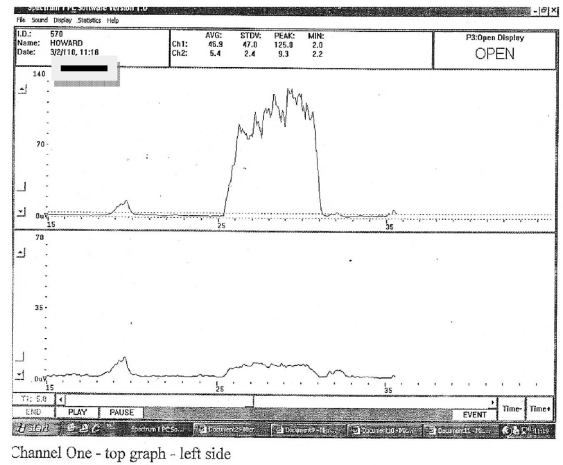

C

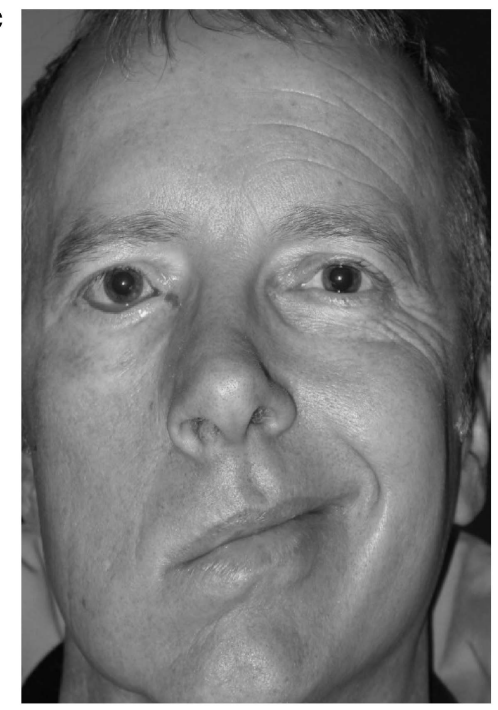

e

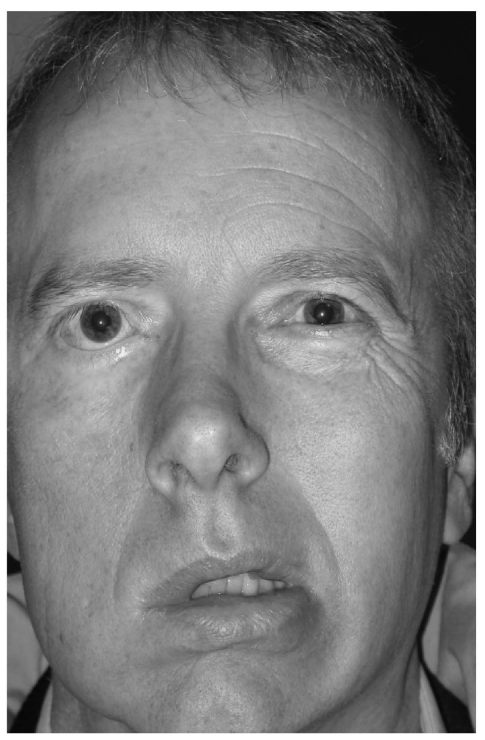

b

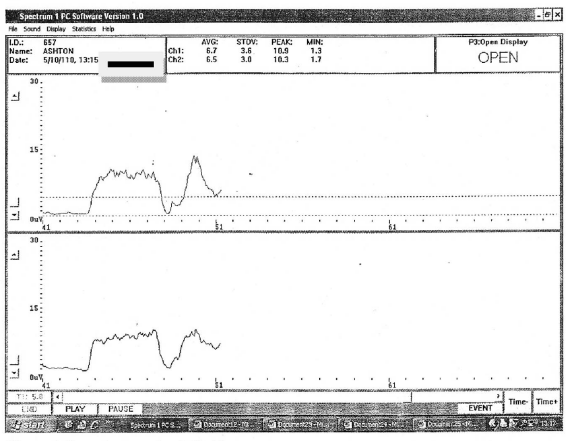

Channel One - top graph - left side

d

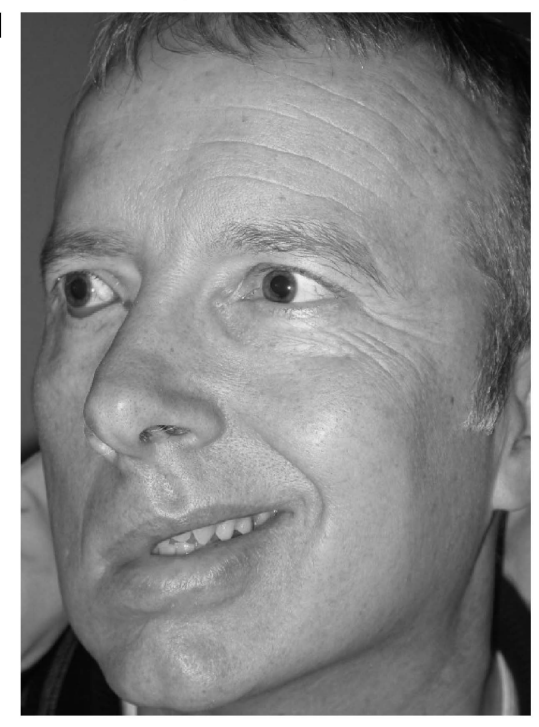

f

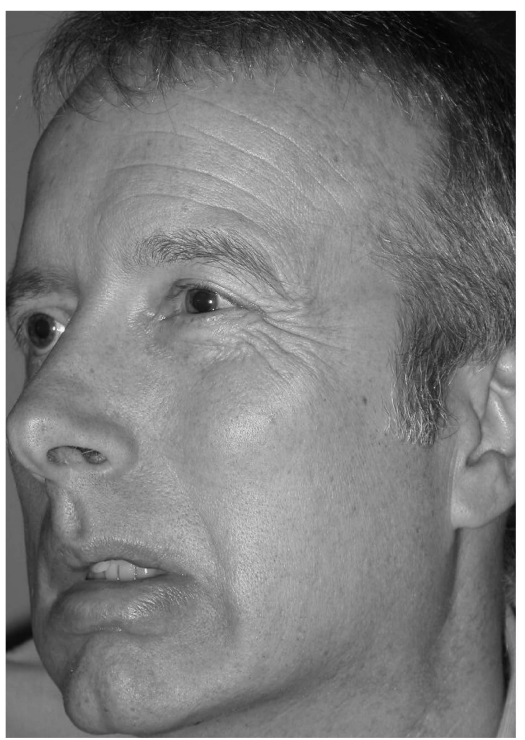

Figure $2(\mathrm{a}, \mathrm{b})$ Pre and post-BTXA EMG study of patient in Figures 2c-f with electrodes on both corners of the mouth and patient smiling. The patient has a right seventh nerve palsy. (c, d) Pre-BTXA injection with displacement of the nose and mouth towards the normal left side of the face at rest and on smiling, respectively. (e, f) Post-BTXA injection given lateral to the left lip showing improved symmetry and less displacement of the nose and mouth. 


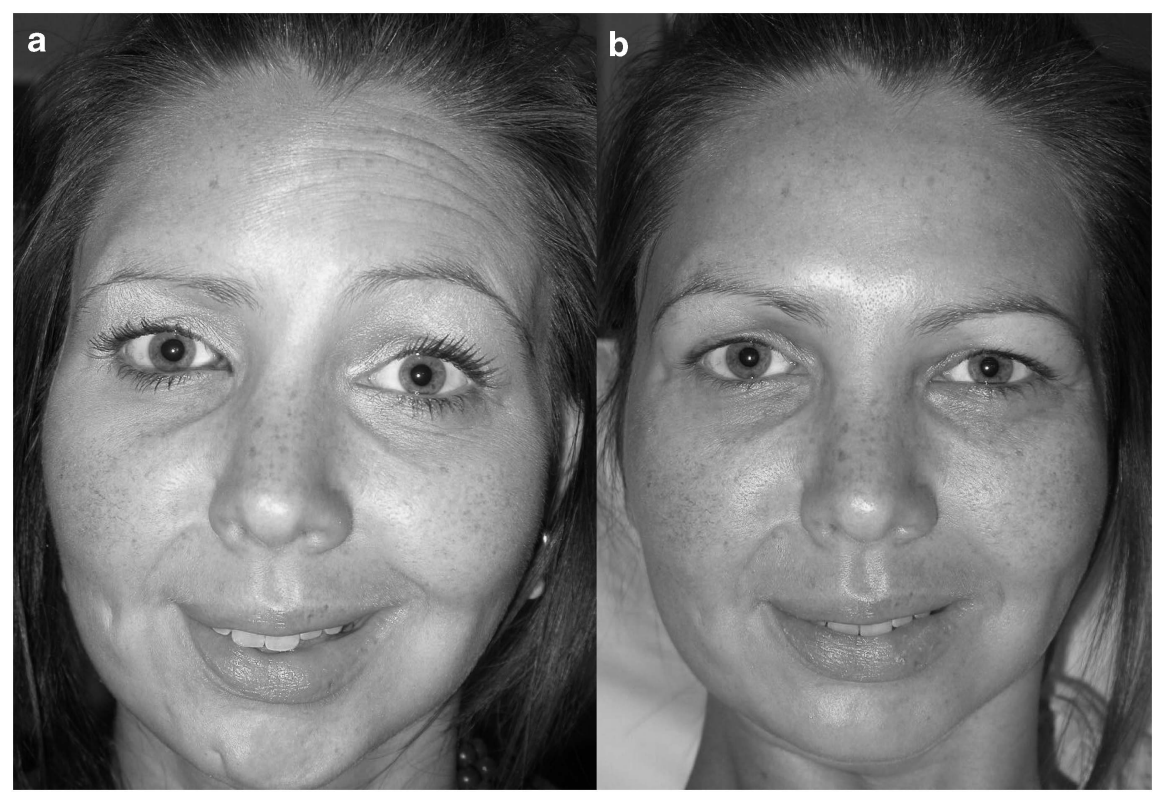

Figure 3 (a) Young patient pre-BTXA with a moderate right sided facial palsy. There is obvious asymmetry when she smiles, laughs, or frowns. (b) After BTXA injections to the left face and forehead, as well as for right synkinesis. There is greatly improved symmetry so the face looks virtually normal.

examining doctor. In addition, patients commented on increased confidence, being more likely to allow photographs taken of themselves, and families reported improved legibility of speech.

The site of the injection will depend on the dynamics of the muscles in each individual patient. Needle EMG is not essential to achieve good results as it does not appear necessary to inject specific muscles, which co-ordinate the smile, but rather the area of activity that contributes most to the movement of the lower face on the normal side during smiling. This most likely involves the DAO of the non-affected side, but also the LLS, risorius, and zygomaticus major and minor.

We found that the average duration of the effect was 13 weeks and the longest duration was 6 months, which is similar to a previous study. ${ }^{7}$ Side effects of drooling were only noted in three patients, but these resolved within a few days, and did not deter patients from further treatment. Other reported side effects resulting from spread of the toxin to adjacent areas were not seen. ${ }^{3}$

\section{Clinical applicability}

Any patient who has an unresolved facial palsy should be referred to a facial palsy clinic where a balanced choice of options can be provided. ${ }^{8}$ Patients not keen on reanimation surgery could be treated with BXTA to improve facial symmetry.

Younger patients naturally have more muscle tone than older patients. As BTXA works by weakening the unopposed pull of the unaffected muscles, the effect is more noticeable and the benefit greater in younger patients. It appears to help all grades of facial palsy, but especially those with partial recovery of lower facial movement (House-Brackmann grades 2 and 3). This latter group are also less likely to undergo facial reanimation surgery where there is always the risk of damage to any residual function on the affected side.

This study highlights the:

- effects of BXTA on improving lower face symmetry when smiling and laughing following injections to the normal side of the face in facial palsy patients

- effective doses needed

- time taken to achieve the peak effect and its duration

- mild self-limiting side effects

- need to tailor the treatment to an individual patient

- EMG studies that confirm the effect of BXTA in balancing the action of the unopposed muscles against the palsied muscles.

Reported patient satisfaction was high although a formal survey was not administered for this treatment as this study was retrospective. Patients commented on an improved smile leading to increased confidence and being more likely to allow photographs to be taken of them. Families reported improved speech articulation.

\section{Conclusion}

Facial nerve palsy is a difficult condition to manage. A multidisciplinary approach is of benefit in our experience. 
The results of this review suggest that BTXA is effective in improving symmetry in patients with facial palsy by injections into the unopposed normal lower facial muscle complex. It is a relatively simple treatment, with a lack of systemic toxicity and provides approximately 3 months of benefit making it acceptable to patients. BTXA should be considered in patients with facial asymmetry because of facial nerve palsies where the maximum expected improvement has been reached and who are not keen for surgical options, particularly younger patients.

\section{Summary}

What was known before

- In facial palsy, paralysis of muscles occurs on the affected side of the face. In contrast, muscles on the unaffected side of the face no longer have opposing forces. This is often cosmetically unacceptable to patients because of asymmetry, especially when speaking, smiling, and laughing. There are significant psychological effects as patients lack the confidence to carry out many daily activities in public, such as appearing in photographs. There are a range of reanimation options available. However, despite these procedures, facial symmetry may not improve.

What this study adds

- This study highlights the: effects of BXTA on improving lower face symmetry when smiling and laughing following injections to the normal side of the face in facial palsy patients; effective doses needed; time taken to achieve the peak effect and its duration; mild self-limiting side effects; need to tailor the treatment to an individual patient; EMG studies that confirm the effect of BXTA in balancing the action of the unopposed muscles against the palsied muscles.

\section{Conflict of interest}

The authors declare no conflict of interest.

\section{Acknowledgements}

This work was supported by the NIHR Manchester Biomedical Research Centre.

\section{References}

1 de Maio M, Bento RF. Botulinum toxin in facial palsy: an effective treatment for contra lateral hyperkinesis. Plast Reconstr Surg 2007; 120(4): 917-927.

2 Bentsianov B, Zalvan C, Blitzer A. Non-cosmetic uses of botulinum toxin. Clin Dermatol 2004; 22: 82-88.

3 Lee C, Kikkawa DO, Pasco NY, Granet DB. Advanced functional oculofacial indications of botulinum toxin. Int Ophthalmol Clin 2005; 45(3): 77-91.

4 Krohel GB, Cipollo CL, Gaddipati K. Contra lateral botulinum injections improve drinking ability and facial symmetry in patients with facial paralysis. Am J Ophthalmol 2005; 139: 540

5 Beurskens CHG, Heyman PG. Mime therapy improves facial symmetry in patients with long term facial nerve paresis: a randomised controlled trial. Australian J Physiotherapy 2006; 52: $177-183$.

6 Coulson SE, Croxson GR, Gilleard WL. Three-dimensional quantification of the symmetry of normal facial movement. Otol Neurotol 2002; 23(6): 999-1002.

7 Salles AG, Toledo PN, Ferreira MC. Botulinum toxin injection in long-standing facial paralysis patients: improvement of facial symmetry observed up to 6 months. Aesthetic Plast Surg 2009; 33(4): 582-590.

8 Sadiq SA, Usmani HM, Saeed SR. Effectiveness of a multidisciplinary facial function clinic. Eye 2011; 25: 1360-1364. 